\title{
AN INVESTIGATION ON THE IMPACT OF ASSEMBLY SEQUENCING ON PRODUCT FAMILY DESIGN OUTCOMES
}

\author{
Shafin Tauhid ${ }^{1}$, Hakan Artar ${ }^{1}$ and Gül Okudan ${ }^{1}$ \\ ${ }^{1}$ The Pennsylvania State University, University Park, USA
}

\begin{abstract}
While many approaches have been proposed to optimize the product family design for measures of cost, revenue and performance, many of these approaches fail to incorporate the complexity of the manufacturing issues into family design decision-making. One of these issues is assembly sequencing. This paper presents a simulation study by which the impact of assembly sequencing on the product family design outcomes is investigated. Overall, the results indicate that when the product family design takes into account the assembly sequencing decisions, the outcomes at the shop floor level improve. The results have implications for companies that are looking into increasing their revenue without increasing their investment in the shop floor.
\end{abstract}

Keywords: Assembly Sequencing, Time Postponement, Form Postponement, Product Family Design.

\section{INTRODUCTION}

Product variety is the diversity of products provided to the marketplace. Mass customization has been adopted by many manufacturing companies which aim to satisfy individual customer needs by introducing product variety while taking advantage of economies of scale. However, as the product variety increases so will the complexity of manufacturing; and hence a company should optimize its external variety with respect to the internal complexity. For this conflicting situation, designing and developing a product family has been recognized as an effective tool.

The proposition of product family is important because it is this design stage when the product quality and production times are determined. This suggests that the underlying principle of product family design can only be fulfilled at the production phase. Despite this fact, however, many approaches to product family design fail to incorporate the complexity of the manufacturing issues into family design decision-making, such as assembly sequencing. Accordingly, we investigate the impact of assembly sequencing for its potential impact on the outcomes of product family design decisions. In the paper, first, we review the published research in this area. Then, we describe the simulation model and the experimental design. Finally, we present the simulation results along with their implication for practice and related future work.

\section{LITERATURE REVIEW}

Whether the ability to create product variety resides within the flexibility of the manufacturing system or within the product architecture, has been a major research topic [45]. Hermann and Chincolkar (2000) [16] proposed that new product design strategies should be tested by manufacturing requirements. Another suggestion by Kusiak and He (1998) [22] was for product design strategies to be tested against production scheduling changes [17]. In general, these suggestions are collected under the idea of designing the product variety in the shop floor. The research of McCutcheon et al. (1994) [29] suggests that companies tailor their products in order to shorten their delivery times. This is called "customization-responsiveness squeeze" [38].

On the other hand, others claim that product designers and process designers pursue different goals (e.g., [13]; [43]). Product designers are usually ignorant of factory capabilities [24]. They fail to recognize the interdependence of these two concepts [44]. The research presented in the paper aims to eliminate this "missing link" between designing and manufacturing for product families. 
Our review of the state of the art is divided into two sections: 1) design, and 2) scheduling. Under the design section, we first summarize the definitions of product family, product architecture, modularity and group technology; and then provide an example, which shows their relation to each other, along with related state of the art pertaining to our research.

\subsection{Design}

The design of a product involves establishing the functional requirements by analyzing customer needs and expectations, creating a design in order to meet these requirements, and facilitating the process to manufacture the design created [7]. In general, tasks undertaken to achieve a design are very complex. For example, [10] characterize the incorporation of both qualitative and quantitative information regarding customer requirements and engineering characteristics as the most important problem to be solved in the new product development. After the completion of the design, manufacturers can establish the set of operations to realize the design. This set of operations is called process information. Process information can be used in order to improve manufacturing traceability, standardization, and quality control while decreasing the cost by utilizing the experiences of previous designs and manufacturing operations. The process information requires product architecture information as an input.

Product architecture is the arrangement of functional elements of a product into several physical building blocks, including the mapping from functional elements to physical components, and the specification of the interfaces among interacting physical components [30]. According to Mikkola and Gassman (2003)[30], there are two types of components: 1) standard, and 2) new-to-firm. Standard components are those that have been used in previous or existing architectural designs by the firm or components that are available from the firm's library of components whereas the new-to-firm components refer to product-specific components that are introduced to the firm for the first time, such as modular innovations [30].

The goals of using standard components are: 1) to minimize investment in product development and tooling, 2) to exploit economies of scale, and 3) to preserve organizational focus leading to specialization and development capabilities [30]. The goals of new-to-firm components, on the other hand, can be classified as: 1) to maximize product performance with respect to customer requirements, 2) to minimize the size and mass of a product- the desire for part integration in order to conserve size and mass gives rise to an integral architecture which implies that components will have to be redesigned, and 3) to minimize the variable costs of production - variables are largely determined by component mass and size [30].

When the design is created using another product as a parent product, it is considered as a member of the product family. The concept of product family is defined by Fan and Liu (1999) [11] as a group of products based on a specific concept or from a standard parent product [7]. It represents the use of common components to create versions for a product. The product family concept is closely related to modularity.

The term modularity defines the act of using some guidelines and standard components among a limited number of products for another product. See Figure 1. Mikkola and Gassman (2003) [30] define modularity as an approach for organizing complex products and processes efficiently by decomposing complex tasks into simpler activities so they can be managed independently. Modularity can also be termed for the use of encapsulated units to meet the dynamic changes being faced by their host system with the aim of identifying independent, standardized, or interchangeable units to satisfy a variety of functions [2]. Modularity has also been argued by Pine et al. (1993) [34] to be the key to achieve of mass customization [6].

In Figure 1, the 12 possible products (alternatives) can be regarded as members of product family. These alternatives would exemplify other members of the same product family. These examples would differ from each other by having different components. A very important remark in this case would be that those different members of family would perform the similar tasks given that their components are coming from similar module group and these similar components bring the similar functionality to the system. However, there would be at least one capability coming from the one component that makes the product member different that would create the differentiation in their functions.

Benefits from modularity includes increased feasibility of product and component change, increased product variety, reduced order lead time, decoupled risks, easier product diagnosis related to maintenance, repair, and disposal [1]. The characteristics of modularity are the use of finite set of components to meet infinite changes of the environment, the establishment of the module by reviewing the similarities among the components, the act of keeping as much independence of resulting cells as possible and the use of different modules for varieties of 
assemblies [1]. The significance of these benefits can be better recognized when the effects to the whole supply chain is examined.

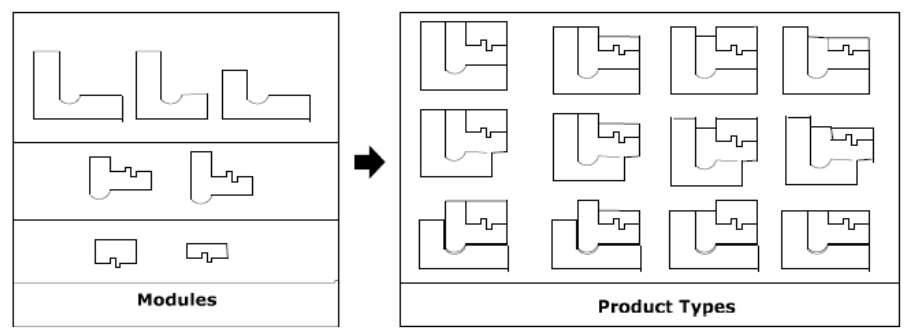

Figure 1. Modular design.

The disadvantages of modularity are redundant product architecture, excessive product similarity, and excessive capability due to designing for the most rigorous application. Forming modules early in the design process is desirable. However, it may cause modules to ignore certain constraints that appear later in the process [21]. Moreover, the benefits of economies of substitution depend on the production volume. In cases when the demand volume is low, high levels of modularity may not be the feasible strategy [30]. Research concluded that modularity management of product architectures should not be conducted in isolation of manufacturing strategy and organizational designs, especially regarding to multi-project management.

Another concept related to product family is "group technology", a method that improves manufacturing efficiency by separating components into part families [31]. The creation of part families follows routing or design information [4]; [32] [1]. Escoto et al. (1998) [9] defined group technology as an identifier and grouper of similar parts into families, and machines into cells for advantages being in the similarity of the parts made in each cell in terms of their design and manufacturing. The benefits of group technology are cited to be simple material flow, cost reduction in material handling, reduction in work in progress, reduction in the cycle time and set-up time, increased manufacturing flexibility, increased quality, and increased job satisfaction [9]. The objective of grouping components was also presented as to maximize the sum of similarities between each component [5]; [27].

In order to simplify explaining the term Group Technology, a good approach would be to go over the term Product Family in reverse. Instead of putting components together to create a product family member, the group technology starts from the member of product family and creates small batches of different but similar components to be manufactured (machined).

The notions of product architecture, product family, modularity and group technology play an important role in our research. While we study the impact of assembly sequencing on the product family design outcomes, we neither want to overlook the impact of assembly sequencing on similar architectures (such as modular designs), or disregard developments in related manufacturing management strategies such as group technology.

The system we have modeled for this investigation has three different products comprising a product family. Our simulation model specifically aids us evaluate the manufacturing statistics for varying assembly sequences and product family designs.

\subsection{Scheduling}

Flexibility of the final assembly process is a key driver of the ability of the firm to offer product variety. The consideration of design during the manufacturing process paying attention to technical constraints has been suggested as a profit enabler [17]. In order to increase this profit, some firms delay the final assembly until the item is ready for shipment. This implementation is called postponement [45]. Postponement is consistently mentioned as one of the central features of mass customization [46]. Two postponement strategies are observed in industry: 1) time postponement, and 2) form postponement. Time postponement (TP) is termed for the strategy that delays the delivery until after the customer orders arrive. It is also commonly referred to as a "'make-to-order" approach [42]. Form postponement (FP), on the other hand, delays the differentiation of the products until later production stages. Form postponement (FP) delays the differentiation of the products until later stages of the supply chain. It requires manufacturers to stock generic (semi-finished) components from which they draw upon for final assembly [42]. 
In the comparisons of TP versus FP, the FP strategy has been found to be more favorable when there is high arrival time and process time variations, meanwhile the TP strategy is more favorable in the situation of increased number of products and high interest rates [42]. When this comparison is extended, it is observed that high utilization levels as a consequence of high arrival time variation and high variation in the process time increases the waiting time of the time postponement strategy. The FP strategy is also more robust to the increases of arrival time variation and variation in the process time because of the stock of generic components. Therefore, as the inter-arrival times become more variable, the FP strategy becomes more attractive. Moreover, it is noticed that high percentage of generic component coverage decreases the waiting time of the FP strategy without affecting the cost. Hence, a company seeking to reduce its customer waiting times and operating in an FP strategy under high utilizations should consider delaying the differentiation of its products as long as possible [42].

Increasing the number of products also increases both the cost and the waiting time of the FP strategy but not those of the TP strategy. Hence, increasing the number of products makes the TP strategy more attractive under both performance metrics. In addition, it is recognized that in the FP strategy, increasing the generic component coverage and reducing the number of products improve the waiting times. Hence, if a firm desires to improve its responsiveness in the FP strategy, allocating resources to product improvement is more effective than process improvement.

Increases in interest rates have a larger impact on the FP strategy than on the TP strategy. This is because the FP strategy (a make-to-stock strategy) has more inventory than the TP strategy (a make-to-order strategy) [42].

Potential changes executed in the scheduling strategies have the ability to affect the profitability of a manufacturing site. A generic name for all scheduling changes would be the routing information. The routing information is the way the product is produced. Examples of such information would be machines, labors and, tools fixtures, and specifications of operation sequences [17]. Thanks to the application of a electronic toothbrush example, this research will investigate the limits of the profitability occurred due to changes made in the scheduling strategies with a simulation study.

The literature review verified that this research will help the manufacturing sites to increase their efficiency level in terms of augmenting the profitability. The research will analyze major counterparts of a manufacturing site from design related issues to scheduling strategies and to profit analysis. The consideration of these counterparts was not done in previous research. This point differentiates this research from previous studies. It is hoped that this research will attract the manufacturer's attention in their iterative quest of improvement.

\section{SIMULATION MODEL DEVELOPMENT}

For the simulation model development, a simple manufacturing system is adopted as shown in Figure 2 . The system is simulated using AUTOMOD version 11.1. The model estimates the incoming order quantities using the quarterly average demand of 1200 units for all products combined. The manufacturing facility produces 3 different types of electronic toothbrushes. Each order consists of demand for any one type of electronic toothbrush (for simplicity). In this study, the 'Vitality Series' toothbrush developed by Oral-B is considered. For any given order, once the required components are manufactured and procured, the product is then assembled, packaged and shipped.

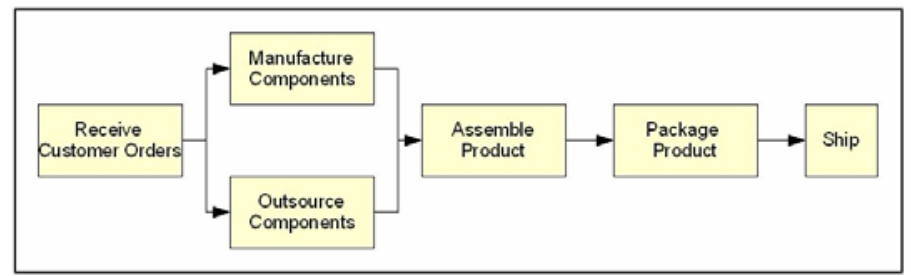

Figure 2. Simulated Manufacturing System.

In time postponement, once a customer order has been received, internal orders (for manufacture of respective components) and external orders (to suppliers for respective components) are placed. Once manufacture is complete and components are delivered from suppliers, the particular toothbrush model is assembled, packaged and shipped. In contrast, for form postponement, a base inventory is used to store components for all toothbrush models. Unlike the TP system, when a customer places an order, the inventory position is the system is checked 
to see if there is sufficient stock of respective components to meet the order. If so, the current inventory levels are decremented, and assembly for desired toothbrush model begins. If not, a backorder is recorded, and based on the inventory position internal and external orders are placed, and an outstanding order for the respective component is recorded. Once assembly begins the model is similar to the TP system. Each time there is any change in current inventory levels; inventory position is checked to see if any internal/external orders are required to be placed. Inventory position is calculated using the following formula:

$$
\text { Inventory position }=\text { Current inventory }+ \text { Outstanding orders }- \text { Backorders }
$$

where, Outstanding Orders are the orders for components that are placed with suppliers and are yet to arrive; and Backorders are customers orders that have not been met by the base inventory and are awaiting delivery/manufacture of components before they can be assembled.

Each toothbrush in the family contains different number of components. The list of components (bill of materials) of all toothbrush models is given in Table 1. In the given table, Parts 6-9 are manufactured in house while the remaining components are outsourced. The in-house manufacturing system consists of four different injection molding machines that produce four different components for all the toothbrush models. Parts 1-3 (shaded in the table), which are outsourced along with Parts 10-11, in the BOM are common to all models, thus forming a product family.

Table 1. Bill of Materials of 'Vitality Series' Toothbrushes (BOM).

\begin{tabular}{|l|l|l|l|}
\hline Part No. & 1. SONIC & 2. DUAL CLEAN & 3. PRECISION CLEAN \\
\hline 1. & Rechargeable Battery & Rechargeable Battery & Rechargeable Battery \\
\hline 2. & Transformer Unit & Transformer Unit & Transformer Unit \\
\hline 3. & AC Charger & AC Charger & AC Charger \\
\hline 4. & Motor & Motor & Motor \\
\hline 5. & IC & IC & IC \\
\hline 6. & Motor \& Battery Casing & Motor \& Battery Casing & Motor \& Battery Casing \\
\hline 7. & Outer Casing & Outer Casing & Outer Casing \\
\hline 8. & Brush Heads & Brush Heads & Brush Heads \\
\hline 9. & Transmission Mechanism & Transmission Mechanism & Transmission Mechanism \\
\hline 10. & & Gear Mechanism & Gear Mechanism \\
\hline 11. & & Transmission Rod & Transmission Rod \\
\hline
\end{tabular}

Process variables for both Time Postponement and Form postponement are listed in Table. 2. Furthermore, key assumptions for both manufacturing strategies are as follows:

1. The system has been modeled to simulate a period of three months, a month consisting of thirty days. Hence the run length for both systems is 2160 hours. A warm-up time of $500 \mathrm{hrs}$ was used.

2. A total of 50 runs are conducted in order to determine a $95 \%$ confidence interval for the system statistics.

3. Downtimes for both systems are ignored, as the objective of the simulation is to determine which postponement strategy is more effective.

4. Customers place orders for only one toothbrush model. The demand for three toothbrush models is assumed to be as: $30 \%$ for Model 1, 35\% each for Models $2 \& 3$.

5. While stocking parts for base inventory or in-process inventory, there are no constraints on floor space and capacity.

6. Change-over setup times between different product models is assumed to be uniformly distributed between 48-72 min for all injection moulding machines, 25-30 min for the assembly machine and 13-17 pm for the packaging machine.

7. Suppliers for all components are assumed to be fairly reliable. Hence, supplier lead times for outsourced components is assumed to triangularly distributed with a min of $14 \mathrm{hrs}$, mode of $15 \mathrm{hrs}$ and max of $18 \mathrm{hrs}$ for 1000 components. Hence, if the order placed to a supplier was for 2000 components, then the supplier lead time would be double of the value obtained from the distribution mentioned above.

8. Once an order is complete it is shipped immediately. Batch shipping is ignored.

9. In both models, there is no batch delivery of components from suppliers. In order words, "cross-ordering" is permitted. 
10. Base inventory levels in Form Postponement are determined using the (s, S) Inventory Policy. For the base case of demand $\mu 1200$ and $\sigma$ 150, it was determined that 'Reorder Point, s' was 900 units and 'Order up to level, S' was 1350 units.

Table 2. Process variables of simulation model for TP \& FP.

\begin{tabular}{|l|l|}
\hline Inter-arrival Time & Exponential $\mu 24$ hours \\
\hline Demand (collective for all models) & Normal $\mu 1200 \sigma 150$ units \\
\hline Processing Time & Uniform $8-12$ hrs per 1000 components \\
\hline Supplier Lead Time & Triangular (Min-14 Mode-15 Max 18) hrs per 1000 components \\
\hline Assembly Time & Uniform $4.85-5.15$ hrs per 1000 components \\
\hline Packaging Time & Uniform $2.75-3.25$ hrs per 1000 components \\
\hline Shipping Time & Exponential $\mu 2$ hours \\
\hline
\end{tabular}

The main purpose of the simulation is to find out what the average lead times in both time and form postponement strategies would be. The assembled entities are recorded with their processed entity numbers and their lead times before they are disposed off of the model. Finally, after all the statistics are recorded, the entities are ready to be disposed by the model for all three product types.

\subsection{Estimation of Demand Rate}

In a study conducted by Biesbrock et. al. [47] on oral health, toothbrush (manual \& electronic) sales revenue in thousands of dollars for quarters in the year 1999 and 2001 have been listed in Table 6 of that paper. Using this data, after a series of calculations, the demand rate has been approximated as follows:

For toothbrushes priced between $\$ 10-\$ 30$

1999 QND Quarter - \$33,611

2001 QND Quarter - \$55,583

With a period of two years an inflation rate of $65 \%$ was observed. Hence, in the current year of 2007, where the dollar value has risen and people are more conscious about oral hygiene, it can be assumed that there would be an inflation rate of $650 \%$ over 2001.

2007 QND Quarter - \$363,354

Using a mean value of $\$ 20$ per toothbrush, the total number of sales of unit toothbrushes would be: 2007 QND Quarter - $18 \mathrm{M}$

Of which $50 \%$ would be electronic toothbrushes 2007 QND Quarter - 9 M

Of which Oral-B would consume $50 \%$ of sales 2007 QND Quarter - 4.5 M

The Vitality series is only one of the ten Oral-B products 2007 QND Quarter $\quad-450,000$ (For Vitality Series)

Of this figure, it is assumed only $25 \%$ of production is carried out at one manufacturing and assembly plant. 2007 QND Quarter - 112,500

A quarter is assumed to consist of 90 days. Hence the average demand per day is approximated to be 1200 units per day.

\section{EXPERIMENTAL DESIGN}

The dependent and independent variables of the investigation are summarized below.

\subsection{Independent Variables}

Four independent variables are considered in the study: 1) assembly sequencing; 2) variation in demand and supplier lead-times; 3 ) the demand; 4) the design of the product family.

\subsubsection{Assembly sequencing}

The assembly scheduling strategies such as time postponement (TP) and form postponement (FP) are tested to observe the total and average lead time. TP requires orders to be put in the process as soon as they arrive. 
Therefore, this strategy would enter the orders in the manufacturing system immediately as they come. On the other hand, FP strategy builds stock of all components. Accordingly, when an order is received some of the components of those orders are already processed. Indeed, TP is make-to-order; and FP is a combination of make-to-stock and make-to-order strategies. Also, TP and FP react differently to changes in independent variables. Hence, for independent variables listed below, the impact on both TP and FP have been analyzed.

\subsubsection{Variations in demand and supplier lead times}

Given fluctuating market conditions, the variation in demand is something that manufacturing facilities should pay attention to in order to maintain their long term profitability. The same can be said for suppliers with regard to lead-times while delivering a component. These variations have an impact on the lead time of orders and hence total cost. The investigation includes higher variations in both demand and supplier lead time to see how both TP and FP respond to greater uncertainty.

\subsubsection{The Inter-arrival Time between Customers}

Alternating inter-arrival times between customer/order arrivals were tested to observe the influences on total costs and average lead times. It is important to know whether larger inter-arrival times between customer arrivals have an impact on manufacturing, and how TP and FP strategies respond to this demand.

\subsubsection{The Design of the Product Family}

The design of the product family can be alternated in order to improve the manufacturing facility performances in terms of total costs and average lead times. In the toothbrush case, the manufacturing site aims to meet the demand for three different members of the toothbrush family. Overall, all toothbrush models cost the same in the market. Thus, technically, a customer who requests model 1 would not have any problem receiving model 2 . Therefore, a manufacturing site should recursively investigate the design of this family according to the changing conditions of the market. It might be more profitable for the manufacturing facility to have less than 3 variants in the family. Although they might be increasing the costs while offering more product variety to the customers at certain times, they might still manage to increase their profits thanks to the advantages of creating a more efficient job shop floor by decreasing the number of product variants within a family.

\subsection{Dependent variables}

A review of the earlier work revealed that mostly either the average lead time or the total production cost for different members of product family were indicated as performance measures in most of these studies. In addition to these two performance measures, work-in-process, inventory, utilization ratios, and average set-up time were also used. Most of the reviewed research work focused primarily on the product family issues from an expense-revenue perspective, and neglected to incorporate the time issues in the studies. This research diverges from earlier work carried out by considering both cost and time. 1) The total cost; and 2) the average lead time; of all three toothbrush models were selected to be employed as the performance measures of the system.

\subsubsection{Total Cost}

The total cost includes the costs of each storing each component and a cost associated with the lead-time for each order. Given that each toothbrush model costs $\$ 18.0$ in the market, it has been assumed that a cost of $\$$ 0.0123 per day is incurred for each component (irrespective of which model that component belongs to) that waits in the inventory before assembly can begin. Furthermore, it has been assumed that the company incurs a penalty cost of $\$ 1.20$ per day ( $\$ 0.05$ per hour) for each toothbrush since an order has been received. Such a costing procedure ensures that major emphasis is placed on lead-times. Since the purpose of this investigation is to ascertain while postponement strategy is more effective production costs have been ignored as they would be the same for both TP and FP systems. This is a very important measuring performance for the manufacturing system because the manufacturing facility only continues to exist as long as it meets the demand for reasonable costs. Therefore, in order to observe the influence of the investigated changes on the manufacturing performance, the total cost variable was used.

\subsubsection{The Average Lead Time}


In addition to the total production cost, the average lead time was used to see how the system was reacting to the changes performed. The average lead time is the total time the toothbrushes spend in the manufacturing facility. It includes the time that components spend in the queues before the machine and assembly and the process time in the machines and assemblies along with packaging and shipping.

\section{RESULTS}

Several simulation runs (50) were performed after the completion of the model creation. Each run was planned to last one production quarter (90 days). Randomly incoming orders were processed in the facility under varying circumstances. Each time the model was run a different random number stream was used. To synchronize customer orders for both models, a dedicated random number steam was used for generating customer arrivals, and another stream was used for shipping of products. For comparing assembly sequencing strategies the results from 50 runs were observed for TP and FP and the difference between them was calculated. Then a 95\% CI was created on the difference as listed in Table 3. From the results it is clear that for the considered manufacturing system, FP is a more effective strategy when compared to TP. Although the inventory costs in FP are higher, the overall total cost is lower as in the lead-time. Hence, maintaining a base inventory level, which is considered a liability in most manufacturing systems, provides a clear advantage when compared to maintaining no inventory at all.

Table 3. 95\% Cl for Time Postponement vs. Form Postponement

\begin{tabular}{|c|c|c|c|c|c|}
\hline & & Leadtime(hrs) & Inventory Cost(\$) & Leadtime Cost(\$) & Total Cost(\$) \\
\hline Time & CI Low & 35.66 & 923 & 226615 & 227544 \\
Postponement & CI High & 36.87 & 1094 & 245211 & 246297 \\
\hline Form & CI Low & 30.62 & 9874 & 196410 & 206386 \\
Postponement & CI High & 33.40 & 10008 & 223497 & 233402 \\
\hline FP vs. TP & CI Low & -5.38 & 8807 & -33521 & -24552 \\
& CI High & -3.13 & 9057 & -18397 & -9500 \\
\hline
\end{tabular}

The simulation model reacted differently to the changes that were performed on the variance in incoming demand and supplier lead-times. The base case, with demand normally distributed with $\mu 1200$ and $\sigma 150$ units and supplier lead times triangularly distributed as (min-14, mode-15, max-18) hrs, was compared to scenarios with demand $\mu 1200$ and $\sigma$ of 250, 350 and 450 units; and then compared to supplier lead-times with (min-12, mode-15, max-20) hrs and (min-10, mode-15, max-25) hrs. The base case was also compared to inter-arrival time (IAT) exponential $\mu 48 \mathrm{hrs}$ and $\mu 96 \mathrm{hrs}$. The results of the different scenarios are tabulated in Table 4 .

Table 4.95\% Cl for Time Postponement vs. Form Postponement in different scenarios

\begin{tabular}{|c|c|c|c|c|c|}
\hline \multirow{2}{*}{$\begin{array}{c}\text { Independent } \\
\text { Variables }\end{array}$} & & \multicolumn{2}{|c|}{ Time Postponement } & \multicolumn{2}{|c|}{ Form Postponement } \\
\hline & & Lead-time(hrs) & Total Cost (\$) & Lead-time (hrs) & Total Cost (\$) \\
\hline $\begin{array}{lr}\mu 1200 & \sigma 150 \\
\text { SLT }(14,15,18)\end{array}$ & $\begin{array}{l}\text { CI Low } \\
\text { CI High }\end{array}$ & $\begin{array}{l}35.67 \\
\mathbf{3 6 . 8 7} \\
\end{array}$ & $\begin{array}{l}227544 \\
246297 \\
\end{array}$ & $\begin{array}{l}30.62 \\
33.40 \\
\end{array}$ & $\begin{array}{l}206386 \\
233402 \\
\end{array}$ \\
\hline$\mu 1200 \sigma 250$ & CI Low & 35.89 & 234213 & 30.21 & 210164 \\
\hline SLT $(14,15,18)$ & CI High & 37.08 & 253006 & 32.75 & 233056 \\
\hline $\begin{array}{lr}\mu 1200 & \sigma 350 \\
\operatorname{SLT}(14,15,18)\end{array}$ & $\begin{array}{l}\text { CI Low } \\
\text { CI High }\end{array}$ & $\begin{array}{l}36.84 \\
38.24 \\
\end{array}$ & $\begin{array}{l}246825 \\
267670 \\
\end{array}$ & $\begin{array}{l}30.05 \\
33.17 \\
\end{array}$ & $\begin{array}{l}216655 \\
242867\end{array}$ \\
\hline $\begin{array}{l}\mu 1200 \sigma 450 \\
\text { SLT }(14,15,18)\end{array}$ & $\begin{array}{l}\text { CI Low } \\
\text { CI High }\end{array}$ & $\begin{array}{l}37.95 \\
39.53 \\
\end{array}$ & $\begin{array}{l}259781 \\
282584 \\
\end{array}$ & $\begin{array}{l}29.47 \\
32.90 \\
\end{array}$ & $\begin{array}{l}222079 \\
258124 \\
\end{array}$ \\
\hline $\begin{array}{l}\mu 1200 \quad \sigma 150 \\
\text { SLT }(12,15,20)\end{array}$ & $\begin{array}{l}\text { CI Low } \\
\text { CI High }\end{array}$ & $\begin{array}{l}34.19 \\
44.82\end{array}$ & $\begin{array}{l}220479 \\
297105\end{array}$ & $\begin{array}{l}33.44 \\
37.22\end{array}$ & $\begin{array}{l}223706 \\
259265\end{array}$ \\
\hline $\begin{array}{l}\mu 1200 \quad \sigma 150 \\
\text { SLT }(10,15,25)\end{array}$ & $\begin{array}{l}\text { CI Low } \\
\text { CI High }\end{array}$ & $\begin{array}{l}39.44 \\
45.06 \\
\end{array}$ & $\begin{array}{l}255145 \\
280411 \\
\end{array}$ & $\begin{array}{l}42.08 \\
49.10 \\
\end{array}$ & $\begin{array}{l}275128 \\
331114 \\
\end{array}$ \\
\hline $\begin{array}{lr}\mu 1200 \quad \sigma 150 \\
\text { IAT e } \mu \quad 48 \text { hrs }\end{array}$ & $\begin{array}{l}\text { CI Low } \\
\text { CI High }\end{array}$ & $\begin{array}{l}33.02 \\
33.67\end{array}$ & $\begin{array}{l}106040 \\
115421\end{array}$ & $\begin{array}{l}31.54 \\
32.37 \\
\end{array}$ & $\begin{array}{l}112227 \\
121081\end{array}$ \\
\hline $\begin{array}{lr}\mu 1200 & \sigma 150 \\
\text { IAT e } \mu & 96 \mathrm{hrs}\end{array}$ & $\begin{array}{l}\text { CI Low } \\
\text { CI High }\end{array}$ & $\begin{array}{l}32.36 \\
33.39\end{array}$ & $\begin{array}{l}52134 \\
58256\end{array}$ & $\begin{array}{l}32.05 \\
32.79\end{array}$ & $\begin{array}{l}58409 \\
64672\end{array}$ \\
\hline
\end{tabular}


With increase in variance of demand, lead-time and total cost for TP tended to increase, especially with $\sigma 450$ units an increase of 2-3 hours was observed. In contrast, in FP there was no significant change as the variance in demand increased. Based on this, one can conclude that FP is more robust than TP with regards to uncertainty in demand. Manufacturing companies along with product designer should study the forecasted demand, and if large variations and uncertainties are expected, FP would be a more effective strategy to implement. However, it is interesting to note that in FP, thought the lead-times do not increase, the total costs rise as the variance in demand increase. This is due to the fact that as variance increases, so does the base inventory level which has been calculated using the (s, S) inventory policy. Despite increased inventory costs, which in turn lead to higher total costs, FP still outperforms TP for all the $\sigma$ values experimented with. With regards to variations in supplier lead times, both TP and FP showed considerable increase in lead-times and costs as the triangular spread was increased. With supplier lead-times at (min-10,mode-15,max-25) hrs TP saw an increase in lead-time of 4-9 hrs while in TP an increase of 12-16 hrs was observed. Both strategies indicated a dependence on supplier leadtimes, more so in FP as it relies heavily on base inventory levels to fulfill customer orders. Product designers are advised to incorporate components that can be procured easily from reliable suppliers. The observed statistics are of utmost importance to manager and process planners so that while designing or running a manufacturing system, because process/demand uncertainties occur on a regular basis; and the most reliable and robust manufacturing strategy should be selected.

With increase in variance of demand, lead-time and total cost for TP tended to increase, especially with $\sigma 450$ units an increase of 2-3 hours was observed. In contrast, in FP there was no significant change as the variance in demand increased. It can be concluded that FP is more robust than TP with regards to uncertainty in demand. Manufacturing companies along with product designer should study the forecasted demand, and if large variations and uncertainties are expected, FP would be a more effective strategy to implement. However, it is interesting to note that in FP, thought the lead-times do not increase, the total costs rise as the variance in demand increase. This is due to the fact that as variance increases, so does the base inventory level which has been calculated using the (s, S) inventory policy. Despite increased inventory costs, which in turn lead to higher total costs, FP still outperforms TP for all the $\sigma$ values experimented with. With regards to variations in supplier lead times, both TP and FP showed considerable increase in lead-times and costs as the triangular spread was increased.

With supplier lead-times at (min-10,mode-15,max-25) hrs TP saw an increase in lead-time of 4-9 hrs while in TP an increase of 12-16 hrs was observed. Both strategies indicated a dependence on supplier lead-times, more so in FP as it relies heavily on base inventory levels to fulfill customer orders. Product designers are advised to incorporate components that can be procured easily from reliable suppliers. The observed statistics are of utmost importance to manager and process planners so that while designing or running a manufacturing system, because process/demand uncertainties occur on a regular basis; and the most reliable and robust manufacturing strategy should be selected.

When the inter-arrival times between customers was increased to exponential $\mu 48 \mathrm{hrs}$ and $\mu 96 \mathrm{hrs}$, as compared to exponential $\mu 24 \mathrm{hrs}$ in the base case, it was observed the lead times TP and FP were similar though the leadtime of TP decreased by approximately $2 \mathrm{hrs}$ as compared to the base TP model. However, both TP and FP showed a dramatic decrease in total costs as compared to their respective original models. With inter-arrival time at $48 \mathrm{hrs}$, total costs dropped by about 121500-130900 for TP and by 94150-112300 for FP. When the interarrival was adjusted to $96 \mathrm{hrs}$ total costs decreased by $175400-188000$ for TP and by 148000-168700 for FP. These results indicate that inter-arrival times between customers have a significant effect on the total costs (though lead-time remains to be same), and companies should try to stagger customer arrivals so as to observe larger profit. It was also observed that with inter-arrival time at $96 \mathrm{hrs}$, the total cost of TP was marginally smaller by about 6000 as compared to FP. From this one can conclude that as the inter-arrival time increases TP becomes a more viable alternative as compared to FP, since stocking of individual components for longer periods of time result in higher base inventory costs for FP.

Finally, different alternatives for product family design were also experimented using the simulation model. The toothbrush models 2 and 3 were tested for alternative replacements in order to test for efficiency. When model 3 was excluded from the system, which means all orders for model 3 would be replaced with model 2 (i.e. $30 \%$ for Model $1 \& 70 \%$ for Model 2), the lead times were not noticeably affected. Considering that all toothbrush models cost the same, such a change in the product family design would not be beneficial for the manufacturer. A similar analysis was made when the facility would manufacture only one toothbrush model (i.e. 100\% orders for Model 
1). Once more, these changes didn't reflect significant improvements in terms of lead times and cost. The results indicate that decreasing or increasing the number of products in a family does not have significant advantages and that the facility is better off by producing all three types of toothbrushes rather than excluding any toothbrush models from their product portfolio. The results of these experiments are listed in Table 5.

Table 5. 95\% Cl for Time Postponement vs. Form Postponement for different number of toothbrush models.

\begin{tabular}{|c|c|c|c|c|c|}
\hline \multirow{2}{*}{$\begin{array}{c}\text { Independent } \\
\text { Variables }\end{array}$} & & \multicolumn{2}{|c|}{ Time Postponement } & \multicolumn{2}{c|}{ Form Postponement } \\
\cline { 3 - 6 } & Lead-time(hrs) & Total Cost (\$) & Lead-time(hrs) & Total Cost (\$) \\
\hline $\boldsymbol{\mu} \mathbf{1 2 0 0} \boldsymbol{\sigma} \mathbf{1 5 0}$ & CI Low & $\mathbf{3 5 . 6 7}$ & $\mathbf{2 2 7 5 4 4}$ & $\mathbf{3 0 . 6 2}$ & $\mathbf{2 0 6 3 8 6}$ \\
Models 1,2 \& 3 & CI High & $\mathbf{3 6 . 8 7}$ & $\mathbf{2 4 6 2 9 7}$ & $\mathbf{3 3 . 4 0}$ & $\mathbf{2 3 3 4 0 2}$ \\
\hline $\boldsymbol{\mu} \mathbf{1 2 0 0} \boldsymbol{\sigma} \mathbf{2 5 0}$ & CI Low & 33.72 & 221954 & 30.88 & 202267 \\
Models 1 \& 2 & CI High & 35.48 & 239174 & 34.59 & 236320 \\
\hline $\boldsymbol{\mu} \mathbf{1 2 0 0} \boldsymbol{\sigma} \mathbf{3 5 0}$ & CI Low & 34.47 & 221778 & 29.43 & 195983 \\
Model 1 only & CI High & 35.51 & 237940 & 30.48 & 210325 \\
\hline
\end{tabular}

\section{CONCLUSION}

This paper aims at providing product designers and process engineers at closer look at how assembly sequencing is impacted by product design and manufacturing uncertainties. As mentioned earlier in the literature review, product designers are ignorant of factory capabilities and that manufacturing complexities are not considered during the design stage. The experiments conducted in this study will allow product designers to consider manufacturing intricacies while deciding the number of product variants within a family, and how time postponement and form postponement strategies respond to the number of variants within the family. The study will also help process engineers to decide which manufacturing strategy should be employed in order to decrease customer lead-times and reduce overall costs. From the obtained results it can be concluded that in most of the experimented scenarios, Form Postponement has a distinct advantage over Time Postponement for the considered manufacturing system. With regard to uncertainties in demand and change in overall demand, FP again seems to be a more robust manufacturing strategy. From a management perspective this is a critical requirement, because while forecasting delivery times to customers, a more robust and reliable strategy would be desired. Another important observation is that both TP and FP models are constrained by supplier lead-times, as higher lead-times were recorded as the spread of supplier lead-times was increased. This means that selecting reliable suppliers is of utmost importance for an effective manufacturing strategy. These conducted experiments should allow manufacturing firms a better insight while making product family related design decisions.

The experiments conducted to observe how FP and TP react to changes in inter-arrival times show that TP seems to be more effective that FP when the inter-arrival times between customers increase as a result in stocking of components in base inventory for longer periods of time which results in increased inventory costs, thus negating the advantage FP has over TP. Furthermore, toothbrush components are relatively inexpensive as compared to aircraft or automobile components, where inventory stocking costs would be extremely high. It can be speculated that TP again would be more efficient than FP when inventory stocking costs are high. However, further analysis is required to substantiate these claims. Also, models that incorporate multi-stage assembly systems should be developed to observe TP and FP manufacturing strategies. In multi-stage assembly system simulation optimization would need to be carried out to determine inventory levels and optimum point of differentiation where lead-times and overall costs can be reduced. Simulation optimization can be carried out in Autostat, the statistical analysis software provided with Automod that uses the modified Genetic Algorithm search heuristic.

\section{REFERENCES}

[1] Alizon, F., Shooter, S. B. and Simpson, T. W., Reuse of Manufacturing Knowledge to facilitate PlatformBased Product Realization, Transactions of Asme, 2006, Vol. 6, pp. 170-178.

[2] Bi, Z. M. and Zhang, W. J., Modularity Technology in Manufacturing: Taxonomy and Issues, International Journal Advanced Manufacturing Technology, 2001, Vol. 18, pp. 381-390.

[3] Bruccoleri, M., Amico, M. and Perrone, G., Distributed Intelligent Control of Exceptions in Reconfigurable Manufacturing Systems, International Journal Production Research, 2003, Vol. 41, No. 7, pp. 1393-1412. 
[4] Burbidge, J. L., Production flow analysis for planning group technology", Clarendon Press, 1989 Oxford.

[5] Catay, B., Vakharia, A. and Erenguc, S., A methodology for component grouping and printed circuit board scheduling in an open shop manufacturing environment, working paper, 2002, http://bear.cba.ufl.edu/vakharia/vita/openshop.doc

[6] Coronado, A. E., Lyons, A. G., Kehoe, D. F. and Coleman, J., Enabling Mass Customization: Extending Build-to-Order concepts to Supply Chains, Production Planning \& Control, 2004, Vol. 15, No. 4, pp. 398411

[7] De Lit, Pierre, An integrated approach for product family and assembly system design, IEEE Transactions on Robotics and Automation, 2003, Vol. 19(2), pp. 324-334.

[8] Durray, R., Ward, P., Milligan, G. and Berry, W., Approaches to mass customization: Configuration and Empirical Validation, Journal of Operation Management, 2000, Vol. 18, pp. 605-625.

[9] Escoto, R. P., McDonnell L. R., Salort, E. V. and Esteban, F. C. L., Development of an Algorithm for the Application of Group Technology in the Design of Manufacturing Systems, Production Planning \& Control, 1998, Vol. 9 (3), pp. 267-274.

[10] Fung, R. Y. K., Chen, Y. and Tang, J., Estimating the functional relationships for quality function deployment under uncertainties, Fuzzy Sets and Systems, 2006, Vol. 157, pp. 98-120.

[11] Fan, I.-S. and Liu, C.-K. Product family and variants: Definition and models," in Flexible Automation and Intelligent Manufacturing 1999, 1999, J. Ashayeri, W. G. Sullivan, and M. M. Ahmad, Eds. New York: Begell House.

[12] Garud, R. and Kumaraswamy, A., Technological and organizational designs for realizing economies of substitution, Strategic Management Journal, 1995, Vol. 16 (Special Issue), pp. 93-109.

[13] Ginn, M. E. and Rubenstein, A. H., The R\&D/production interface: a case study of new product commercialization, Journal of Product Innovation Management, 1986, Vol. 3, pp. 158-170.

[14] Golany, B., Dar-El, E. M. and Zeev, N., Controlling shop floor operations in a multi-family multi-cell manufacturing environment through constant work-in-process, IIE Transactions, 1999, Vol. 31, pp. 771781.

[15] Heikkila, A. and Koivo, H., Modular control system with intelligent scheduling, Computers in Industry, 1998, Vol. 36, pp. 75-81.

[16] Hermann, J.W. and Chincolkar, M.M., Design for Production: A Tool for Reducing Manufacturing Cycle Time, ASME Design Engineering Technical Conferences, 2000, Paper No. DFM-14002, Las Vegas, NV.

[17] Jiao, J. and Tseng, M.M., Customizability Analysis in Design for Mass Customization, Computer-Aided Design, 2004, Vol. 36(8), pp. 745-757.

[18] Jiao, J., Zhang, L. and Pokharel, S., Coordinating Product and Process Variety for Mass Customized Order Fulfillment, Production Planning \& Control, 2005, Vol. 16 (6), pp. 608-620.

[19] Kattan, I., Mikolajczak, B., Kattan, K. and Alqaassar, B., Minimizing Cycle Time and Group Scheduling using Petri Nets a study of heuristic methods, Journal of Intelligent Manufacturing, 2003, Vol. 14, pp. 107121.

[20] Krishnan, V. and Gupta, S., Appropriateness and impact of platform-based product development, Management Science, 2001, Vol. 47(1), pp. 52-68.

[21] Kusiak, A, Integrated Product and Process Design: A Modularity Perspective, Journal Engineering Design, 2002, Vol. 13(3), pp. 223-231.

[22] Kusiak, A. and He, D.W., Design for Agility: A Scheduling Perspective, Robotics Computer Integer Manufacturing, 1998, Vol. 14(4), pp. 415-27.

[23] Lambert, S. Abdulnour, G. and Drolet, J., Flexibility Analysis of a Surface Mount Technology Electronic Assembly Plant: An Integrated Model Using Simulation, International Journal Flexibility Manufacturing System, 2006, Vol. 17, pp. 151-167.

[24] Langowitz, N.S., An exploration of production problems in the initial commercial manufacture of products, Research Policy, 1988, Vol. 17, pp. 43-54.

[25] Li, E. Y., Shaw, W., H. Jr. and Martin-Vega, L. A., Flow-time of Modified Scheduling Heuristics in a dynamic rescheduling environment, Computers Industrial Engineering, 1996, Vol. 31 (1/2), pp. 213-216.

[26] Li, H, Azarm, S., An Approach for Product Line Design Selection under Uncertainty and Competition, Journal of Mechanical Design, 2002, Vol. 124, pp. 385-392. 
[27] Lourenco, L. L. and Pato M. V., An Improved Genetic Heuristic to Support the Design of Flexible Manufacturing Systems, Computers \& Industrial Engineering, 2004, Vol. 46, pp. 141-157.

[28] Mangun, D. and Thurston, D. L., Incorporating Component Reuse, Remanufacture, and Recycle Into Product Portfolio Design, IEEE Transactions on Engineering Management, 2002, Vol. 49 (4).

[29] McCutcheon, D. M., Raturi, A. S. and Meredith J. R., The customization-responsiveness squeeze, Sloan Management Review, 1994, Vol. 35 (2), pp. 89-99.

[30] Mikkola, J. H. and Gassman, O., Managing Modularity of Product Architectures: Toward and Integrated Theory, IEEE Transactions on Engineering Management, 2003, Vol. 50 (2), May 2003.

[31] Mitrofanov. S. P., The scientific principles of Group Technology, National Lending Library Translation, 1966.

[32] Offodile, O. F., Application of similarity coefficient method to parts coding classification analysis in Group Technology, Journal of Manufacturing Systems, 1991, Vol. 10(1), pp. 442-448.

[33] Park, J., Methods for incorporating cost information into platform-based product development, Pennsylvania State University, 2005, PhD Thesis dissertation.

[34] Pine, J., Victor, B. and Baynton A., Making mass customization work, Harvard Business Review, 1993, Vol. 71, pp. 108-119.

[35] Rhee, I., A modular algorithm for resource allocation, Distributed Computing, 1998, Vol. 11, pp. 157-168.

[36] Saitou, K., Malpathak, S. and Qvam, H., Robust Design of Flexible Manufacturing Systems using Colored Petri Net and Genetic Algorithm, Journal of Intelligent Manufacturing, 2002, Vol. 12, pp. 339-351.

[37] Salum, L., The Cellular Manufacturing Layout Problem. International, Journal Production Research, Vol. 38 (5), pp. 1053-1069.

[38] Salvador, F., Forza, C. and Rungtusanatham, M., Modularity, product variety, production volume, and component sourcing: theorizing beyond generic prescriptions, Journal of Operations Management, 2002, Vol. 20, 549-575.

[39] Salvador, F. and Forza, C., Configuring products to address the customization-responsiveness squeeze: A survey of management issues and opportunities, International Journal Production Economics, 2004, 273291.

[40] Sanchez, R., Modular architectures in the marketing process, Journal of Marketing, 1999, Vol. 63 (Special Issue), pp. 92-111.

[41] Shirley, G.V., Models for managing the redesign and manufacture of product sets, Journal of Manufacturing and Operations Management, 1990, Vol. 3 (2), pp. 85-104.

[42] Su, J. C.P., Chang, Y. and Ferguson, M., Evaluation of postponement structures to accommodate mass customization. Journal of Operations Management, 2005, Vol. 23, 305-318.

[43] Susman, G.I. and Dean Jr., J.W., Development of a model for predicting design for manufacturability effectiveness, In: Susman, G. (Ed.), Integrating Design and Manufacturing for Competitive Advantage. Oxford University Press, 1992, Oxford, New York (Chapter 12).

[44] Swink, M., Completing projects on-time: How project acceleration affects new product development, Journal of Engineering Technology Management, 2003, Vol. 20, pp. 319-344.

[45] Ulrich, K., The role of product architecture in the manufacturing firm, Research Policy, 1995, Vol. 24(3), pp. 419-440.

[46] Van Hoek, R. I., The rediscovery of postponement: a literature review and directions for research, Journal of Business Logistics, 2001, Vol. 19(2), pp. 161-184.

[47] Biesbrock, A.R., Bayuk, L.M., Santana, M-V., Yates, D.S. and Bartizek, R.D., The clinical effectiveness of a novel power toothbrush and its impact on oral health, The Journal of Contemporary Dental Practice, 2002, Vol. 3(2), pp. 001-010. 